IS YOUR MARRIAGE "LEGITIMATE?”:

A CRITICAL DISCOURSE ANALYSIS OF

CANADA'S POLICY ON MARRIAGE FRAUD

by

Vanessa Dullabh, Hons. BA, York University, 2012

\author{
A Major Research Paper \\ presented to Ryerson University
}

in partial fulfillment of the requirements for the degree of

\author{
Master of Arts \\ in the Program of \\ Immigration and Settlement Studies
}

Toronto, Ontario, Canada, 2013

(C) Vanessa Dullabh 2013 


\section{AUTHOR'S DECLARATION FOR ELECTRONIC SUBMISSION OF A MRP}

I hereby declare that I am the sole author of this Major Research Paper. This is a true copy of the MRP, including any required final revisions, as accepted by my examiners.

I authorize Ryerson University to lend this MRP to other institutions or individuals for the purpose of scholarly research.

I further authorize Ryerson University to reproduce this MRP by photocopying or by other means, in total or in part, at the request of other institutions or individuals for the purpose of scholarly research.

I understand that my MRP may be made electronically available to the public.

Vanessa Dullabh 


\title{
IS YOUR MARRIAGE “LEGITIMATE?”: \\ A CRITICAL DISCOURSE ANALYSIS OF \\ CANADA'S POLICY ON MARRIAGE FRAUD
}

\author{
Vanessa Dullabh \\ Master of Arts 2013 \\ Immigration and Settlement Studies \\ Ryerson University
}

\begin{abstract}
As of 2012, Canada has implemented a "conditional probationary period" for sponsored spouses or partners through immigration, influenced by a similar policy in the United Kingdom, geared to prevent fraudulent marriage. I will present a critical discourse analysis of the current policies in both the UK and Canada by reviewing the policies, parliamentary debates, media representations, and official statistics. A major finding is that defining a "genuine" or "legitimate" relationship requires such extensive knowledge of all cultures and traditions by immigration officials, that it can become problematic. I use the theoretical frameworks of biopower by Foucault (1978) and orientalism and othering by Said (1978), to explain government control on immigration as well as the control of relationships between spouses and partners, aimed at creating a specific desired population for Canada and the UK.
\end{abstract}

\section{Key words:}

Immigration; fraudulent marriage; biopower, orientalism, othering 


\section{ACKNOWLEDGEMENTS}

I would like to thank my supervisor, Vappu Tyyskä for her continuous guidance and support during the course of this year. Vappu Tyyskä strengthened my confidence in writing on this topic and was always available for me along with my second reader, Cheryl Teelucksingh for her mentorship and aid throughout the year. I am grateful to past professors and teachers who have inspired me to continue learning and to develop my thoughts. Lastly, I would like to thank my parents, siblings, closest friends and family for their everlasting love and support. 


\section{TABLE OF CONTENTS}

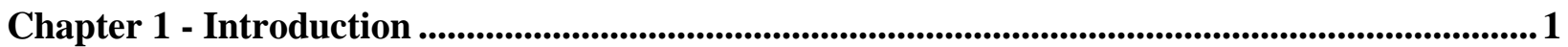

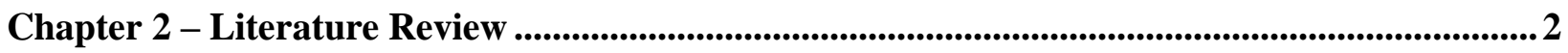

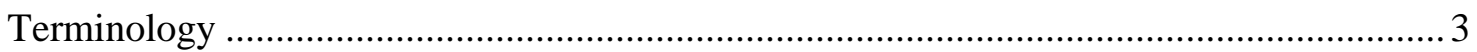

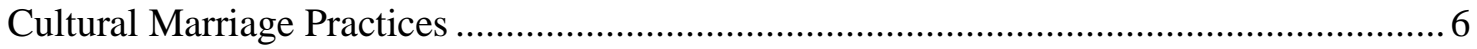

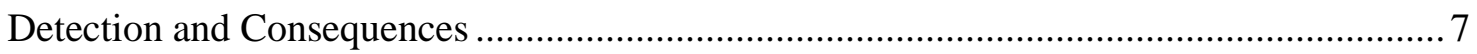

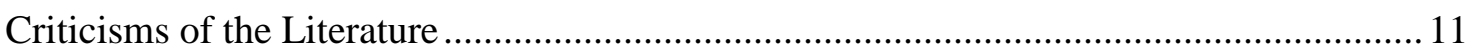

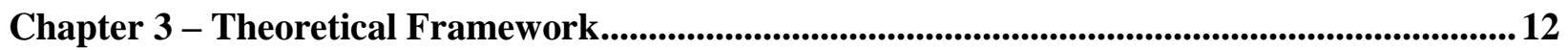

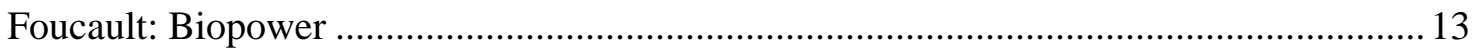

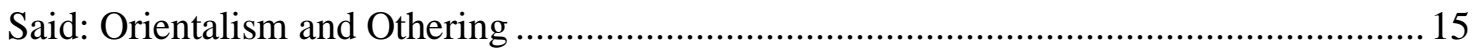

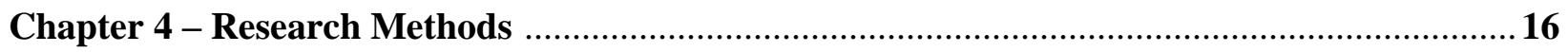

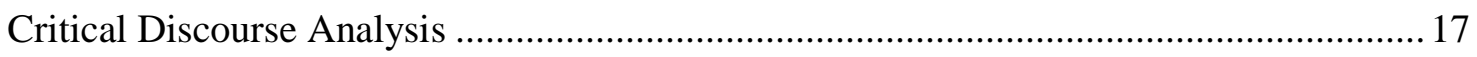

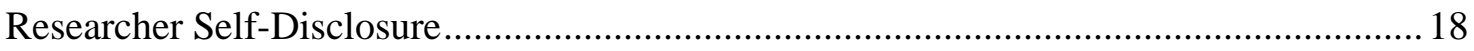

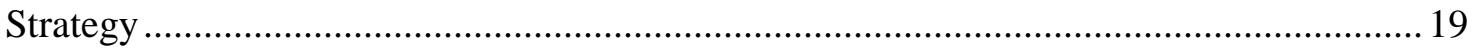

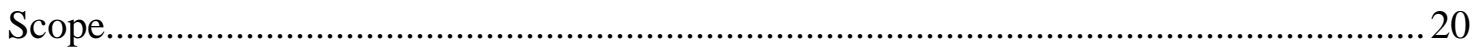

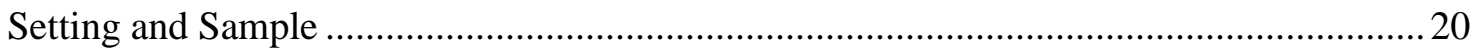

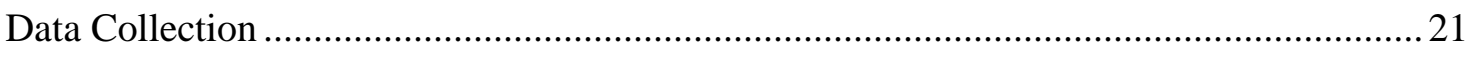

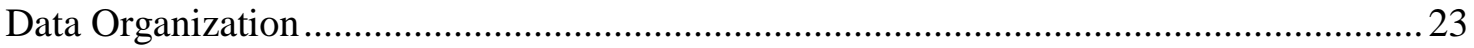

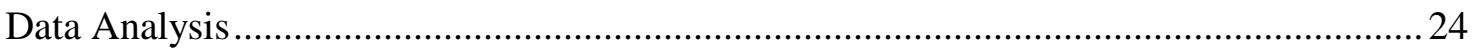

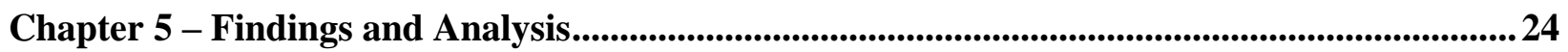

Legislative and Policy Depictions ......................................................................... 25

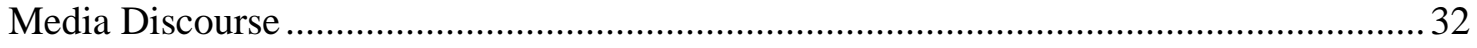

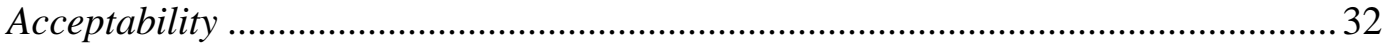

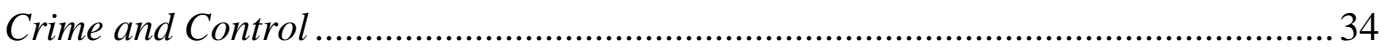

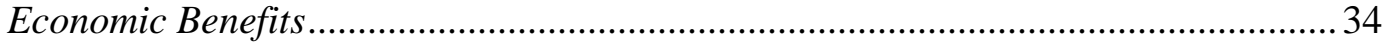

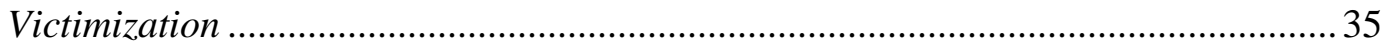

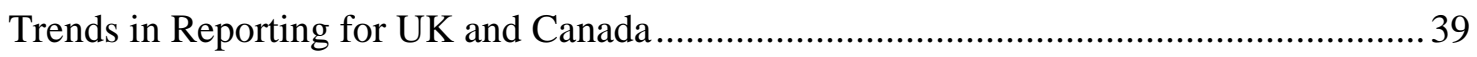

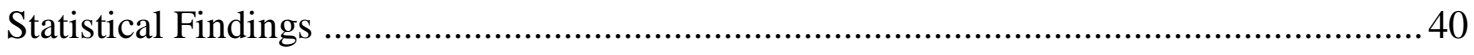

Chapter 6 - Conclusion ....................................................................................................................................... 42

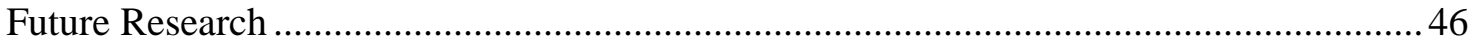

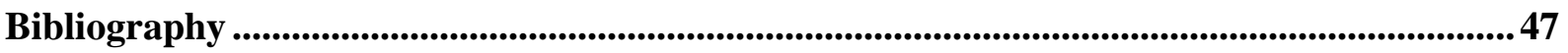




\section{CHAPTER 1: Introduction}

Citizenship and Immigration Canada (CIC) has recently stressed the importance of tackling marriage fraud. Citizenship, Immigration and Multiculturalism Minister Jason Kenney announced on October 26, 2012 that "The jig is up on marriage fraud...marriage should not be a commercial transaction" (Citizenship and Immigration Canada, 2012). As outlined by CIC, the Immigration and Refugee Protection Act (IRPA) is meant to reunite families, and this process allows for a spouse or partner to be sponsored by a Canadian citizen. CIC is recognizing a trend of fraudulent marriages as a way to side-step the immigration. While in 2009 , almost 45,000 people immigrated to Canada as spouses, Aulakh (2010) reports that over 1,000 cases of marriage fraud are reported each year. The response to this trend, as of late 2012, is a piece of legislation that states that spouses or common-law conjugal partners who are in a relationship of less than two years (without children) are subject to conditional permanent residence which requires the spouse or partner to cohabit in a "legitimate" relationship with their sponsor for a period of two years after receiving permanent residence status in Canada (Citizenship and Immigration Canada, 2012). Along with Canada, the United States of America (USA), United Kingdom (UK) and Australia are facing similar issues of immigration fraud through marriage. The new Canadian legislation borrows the concept of the mandatory probationary period from the United Kingdom where this policy was implemented earlier in July of 2012.

The implications of marriage fraud can be recognized on behalf of the state as well as the individual. Canada, as a state needs to recognize that by being a developed nation, many people will go to great lengths in order to be in the country. However, some people may take advantage of the immigration system and Canada's advertized commitment to family reunification. The purpose of this research is to outline the ways the new policy implemented by the Canadian 
government will affect spouses and partners. By considering the multiple facets of relationships and cultural expectations, I will discuss the shortcomings of the policy. In addition, I will analyze the policy through Michel Foucault's (1978) theoretical framework of biopower. I will first include a literature review to better understand the topic, which includes the terminology used by both the United Kingdom and Canada, and an outline of cultural marriage practices, along with the issues involved in the detection and consequences of marriage fraud. The literature review and discussion of biopower will be followed by a critical analysis of my findings related to media discourse, statistics and the policy contents.

\section{CHAPTER 2: Literature Review}

In this section, I will review the relevant literature surrounding the topic of fraudulent marriage. Due to the recentness of the topic, there is little Canadian literature. Many of the sources are government documents and articles gathered from media sources. Each of these sources is subject to criticism and will be further critiqued in the duration of the paper. The dearth of this topic in Canadian literature allows me as a researcher to create a timely and relevant analysis of fraudulent marriages. This chapter begins with outlining terminology and defining terms used within the discourse of fraudulent marriage in the UK and Canada. This will be followed by a discussion of different cultural marriage practices which may challenge or influence the understanding of fraudulent marriage. Finally, I will discuss some of the ways the UK and Canada detect fraud and their consequences. 


\section{Terminology}

The terminology surrounding the topic of fraudulent marriage is broad and inconsistent. As discussed by Archer and Berdahl (2006), terms can be used in a way that presupposes others and the way they understand and agree with the desired conceptualization. The terms being discussed to identify the act of marriage within this literature include: bad-faith relationships, forced marriage, marriage of convenience, fraudulent marriage, and sham marriage. Each of these implies that "spouse" is taking advantage of both the law and the sponsor to sidestep Canada's immigration policies (Citizenship and Immigration Canada, 2010). For example, a badfaith relationship describes a contractual relationship where one party will "destroy a promisee's opportunity to reap the expected benefit of the bargain even though that conduct failed to violate expressed provisions of the agreement" (Diamond, 1981). A "marriage of convenience" is defined as "relationships that are not genuine and that were entered into primarily to obtain immigration status. This can happen when a couple pretends to be in a genuine relationship so that the sponsored partner can come to or stay in Canada. In some cases, the sponsor may be given a financial or other kind of benefit in exchange for the sponsorship" (Citizenship and Immigration Canada, 2010). Damian Green, a conservative Member of Parliament in the United Kingdom, has used the term "sham marriage" and defines it as "an attempted way of gaining long-term residency and the right to work and claim benefits. They involve situations where a non-European national marries someone from the European Economic Area, including the UK" (United Kingdom Border Agency, 2011). It is evident through these definitions that the terminology describes a negative approach to marriage and a dishonest approach to immigration. The definition provided by Damian Green distinguishes how the act of marriage can be misused 
exclusively by non-Europeans. This limited definition targets specific countries, and ethnicities while excluding the possibility of Europeans needing to commit marriage fraud.

For the purpose of paper, I will refer to the phenomenon under investigation, as "marriage fraud" because the Canadian government uses this term in the majority of their public documents. As mentioned above, there are multiple terms used to understand marriage fraud for immigration purposes, and the research for this paper has included all of the terms mentioned in order to gain a wide understanding of the issue from multiple perspectives and bodies of literature. For the duration of this paper, I will use the term "spouse" although it will refer to either: spouse, common-law or conjugal partner. I use the term spouse as it directly corresponds to marriage and is commonly understood amongst the literature. The use of this term is not intended to diminish the acceptance or awareness of any type of relationship between two people.

The literature also interchangeably uses the following terms: visa applicant, sponsored spouse, partner, foreigner and conjugal partner to discuss the people that are seeking methods to come to a Western country such as Canada, US or UK. These terms also identify the outsider (Curry, 2008), and is a feature of the process of "othering". Each of these terms can be constructed differently depending on the goal and political position of the articles or author. For example, Greenhill uses the term "foreigner" to describe the person attempting to fraudulently achieve immigration to the UK (Greenhill, 2010). The tone and the use of this specific term creates an "other" and reinforces the concept of "foreign" which intentionally discriminates against fraudulent marriages and the people involved (Said, 1978). 
The term "victim" is also used quite often to reference the sponsor who may be taken advantage of or "duped" into the marriage (Chetrit, 2012). The term "victim" is consistently and most prevalently used in Canadian newspaper articles. Chetrit states that the victims of marriage fraud are fooled into believing their seemingly love-marriage is genuine. As further discussed by Curry, the "victim" is the sponsor who is used for immigration purposes, and is often depicted as being broke and broken-hearted (Curry, 2008). Citizenship and Immigration Canada recognizes this one-sided action as "victimization" of fraud; this includes sponsors taking on offers of money, rewards, or promises of love in order to enter into marriage. While understanding the term "victim," it should be noted that some people may be forced into committing marriage fraud, and in this situation, the sponsored spouse would also be considered a victim. An example of this is "forced marriage" which will be discussed in greater detail later on.

Miller-Muro describes a different use of the term "victim" by associating it with battered spouses in terms of abuse (Miller-Muro, 2011). Merali (2009) responds to the domestic abuse situation in Canada by acknowledging the dependence of the sponsor in the immigration process, and that spouses can be threatened with deportation during the mandatory probationary period (Merali, 2009). Although the Canadian Violence Against Women Act contains a clause for immigrant spouses to protect them against the vulnerabilities such as abuse and lack of access to resources, it is recognized by Miller-Muro that a power imbalance may still be manifested in the difficulty of accessing services, and language barriers which can contribute to the victimization of some immigrant spouses (Canadian Council for Refugees, 2012). It is also important to distinguish between "victims" in each of the contexts as the negative actions range from financial troubles to physical or sexual abuse. The complex definition of "victim" is similar to the representation of "foreigner" as mentioned earlier. 


\section{Cultural Marriage Practices}

The practices of fraudulent marriages are perceived differently by authors. There is a focus on cultural definitions of marriage which may appear to be a form of fraudulent marriage. This section will review a few of the forms of marital relationships which may affect the immigration process and may ultimately be categorized as fraudulent marriage. To recall Green's definition of a fraudulent marriage, he addresses the concept of a non-European national marrying someone from the European Economic Area (United Kingdom Border Agency, 2011). This definition clearly outlines the "other" and fails to recognize the cultural aspects of marriage for some Europeans, with applications to Canadians. Zaidi and Shuraydi discuss the ways that Western families still perform traditional practices such as arranged marriage as a way to maintain social tradition, religious beliefs, and to allow for social obligations towards family, community and society for South Asian families (Zaidi \& Shuraydi, 2002). The tradition of arranged marriages may involve marrying a spouse from the "home country" which is most likely a non-European country (Zaidi \& Shuraydi, 2002). While this tradition can fit into Green's definition of a fraudulent marriage because of the sponsor marrying a non-European, it does not necessarily mean that there are intentions to abuse the Western immigration system. This concept of "other" is highly prevalent in the literature and it is often associated with a racialized group. It is my personal observation, in keeping with the analysis of Said (1978), that they are also criminalized because they are seen as taking advantage of the immigration system and using the act of marriage solely for the purposes of immigration.

Another practice that is mentioned within the literature is mail-order brides. This practice as defined by Belleau (2003) and the IRPA (2011) to include brides who marry their consumerhusbands in the bride's home country before immigrating to Canada. This practice is highly 
focused on Eastern-European and Asian countries. The consumer-husband refers to the man who will essentially pay for a woman to become his wife from another country. Obtaining a spousal visa for a mail-order bride raises questions relating to the definition of a spouse, and the in/validity of a foreign marriage. This process further complicates the concept of "cultural practice." Belleau effectively discusses the many ways in which mail-order brides are subject to "victimization" including physical and sexual abuse once they arrive to their new homes with their spouses. There are obvious parallels between the mail-order bride and the arranged marriage as in both cases, the outsider spouses are seen as vulnerable to dominance and abuse in their marital relationships. This parallel is also discussed by Lu (2005), as she understands the stakes and complex transitions that occur mainly for women as they partake in "cross-border marriages."

Thus, the cultural and traditional approaches to marriage face scrutiny by immigration officials. Qayyum (2010) states that many couples in arranged marriages do not meet until their wedding, therefore these unions may falsely raise flags about immigration fraud, and the applications can be refused. Qayyum explains that many of these relationships can take place over phone calls for a short period of time and move towards engagements only after a few months. This difference from Western culture is highlighted because many of these genuine marriages occurring mainly in South Asia do not match normalized Canadian views which can raise "red flags" for visa officers (Qayyum, 2010).

\section{Detection and Consequences}

As discussed above, fraudulent marriage is seen as a method to side-step the immigration process. The Canadian Border Service Agency (CBSA) reported that in 2009, 14,762 people 
were deported; however there are no statistics as to how many of them were deported for marriage "misrepresentation" (Aulakh, 2010). The CBSA also reported that 70 percent of cases reporting fraudulent marriage are South Asian (Aulakh, 2010); however they did not provide an exact number to determine the actual magnitude of the phenomenon. The detection of fraudulent marriage is often placed at the discretion of immigration officers; however there are also many tools to aid the detection process, some involving information technology. The United Kingdom implemented a specific division within the UK Border Agency to investigate foreign marriages. The findings indicated that specifically religious officials in some churches were "in on the sham" by performing multiple fraudulent marriages; other forms included fake passport stamps to make it seem as if the sponsor had travelled to the country of the spouse to get married, and obtained false wedding certificates (Greenhill, 2010).

Along with the government tracking physical documents and interviews conducted by the UK officials, the United States' Department of Homeland Security revealed the importance of social networking sites as a form of Fraud Detection and National Security (FDNS). Bosker outlines the memo by FDNS by stating that social networking allows authorities to browse the sites to see if petitioners and beneficiaries are in a legitimate relationship (Bosker, 2010). Although the actions taken on by FDNS seem to be in the best interest of the state, it is important to question whether the privacy of the citizens is being upheld. This type of surveillance is evidently in the best interest of the state; however Bosker states that the memo distributed by the FDNS does not mention what level the suspicion must be at, before conducting this surveillance which may essentially affect all applicants (Bosker, 2010). In keeping with this trend, the Canadian government has implemented a whistle-blower campaign that allows people to anonymously report fraudulent marriages to the government (Citizenship and Immigration 
Canada, 2010). Although Bosker argues that privacy is important to citizens, she does not discuss whether the visa applicant's privacy is being compromised. By not including both sides of the debate, Bosker's article does not fully investigate fraudulent marriages and the fluidity of privacy in terms of protection of the citizen as opposed to the sponsored spouse.

There is a lack of literature surrounding the detection of "legitimate" relationships. It is possible that the government will not release all forms of investigations, or that the definition of "legitimate" is fluid and undefined, which is also a critique of the policy. To define "legitimacy" or a "genuine" marriage would require the government to list qualities that do and do not constitute a relationship. In recognizing the definition of fraud, it is important for the policies and literature to define "legitimate" and "genuine" relationship in regards to immigration, which can effectively create a policy with clear guidelines and an objective and impartial selection process. CIC states that there are immigration officers that are trained to understand multiple cultural definitions of "legitimate" relationships (Citizenship and Immigration Canada, 2010). Although CIC has seemingly identified this weakness, it does not mean that it has effectively been resolved. It is arguable that it is impossible for an immigration officer to be trained in every culture, or identify a relationship based on cultural norms. The understanding of a relationship is quite difficult because it is both a cultural practice and a personal experience for people.

Detecting marriage fraud does not always imply that both parties in the relationship are committing fraud. As mentioned earlier, CIC recognizes this one-sided action as "victimization" of fraud, including sponsors taking offers of money or promises of love in order to enter into marriage. CIC also warns that the government may not be able to detect all forms of marriage fraud due to the fluidity in defining relationships and lack of resources, and therefore each 
sponsor is financially responsible for their spouse for up to two years even if the marriage fails (Citizenship and Immigration Canada, 2012).

Visa applicants and sponsors may acquire a criminal record if it is determined that the marriage is fraudulent. CIC recognizes that some marriages can naturally fail without being illegitimate at the time of the wedding. However, Canada Border Services Agency reports that investigations will be conducted and enforcement may mean deportation (Citizenship and Immigration Canada, 2012). Qayyum (2010) and Belleau (2003) heavily focus on the threat of deportation. These authors discuss deportation as a negative consequence to marriage fraud because it places the visa-applicant at risk by making them vulnerable and in fear of authority. It is also necessary to understand that deportation is the ultimate threat and response to immigration fraud by the government. Due to the policy change, it is evident that CIC and the Royal Canadian Mounted Police (RCMP) are working together to detect and tackle marriage fraud. In 2008, "Operation Conjugal" was initiated to detect fraudulent marriage. Due to the difficulty of detecting marriage fraud, it is noted that many of the investigations are initiated through anonymous information. The investigations take place through levels which include interviews, system checks, surveillance, and surprise visits depending on where the applicant is located in Canada or overseas (Keung, 2013).

In addition, there are macro-level consequences to marriage fraud. Currently, CIC reports that it is costly to conduct interviews at missions abroad, and to determine which cases should be prioritized, and work to prevent further burden on the system (Citizenship and Immigration Canada, 2010). Although visa officers are trained to assess relationships based on customs, traditions and practices of other cultures, it seems that if a relationship is misinterpreted, the concept of family reunification is defeated. This leaves room for fraudulent relationships to "pass 
the test" because they meet the standards of the visa officer. This type of system may burden and threaten the effectiveness of family reunification.

\section{Criticisms of the Literature}

Most of the sources retrieved from scholarly databases may not be considered academically sound because they are written for newspapers and other media sources which are geared towards a general population, rather than an academic audience. Newspapers may be considered an unreliable source due to un-sourced credibility and the fact that they may not be peer-reviewed (Potter \& Levine-Donnerstein, 1999). However, they are the most current reports of the legislation and offer a view to the issues and how they affect people, through anecdotal context information. In addition to the newspaper articles, many of the sources are government official documents. Although this can be considered a strength because it is factual information from a reliable source, in my view it also narrows the perspective and may be presented in a way to convince the public that all of the decisions are correct and beneficial for the country.

Media sources demonstrate the stance that fraudulent marriages are a burden on the immigration system. Although the sources may discuss anecdotal cases, none of the research provides statistics on how many fraudulent marriages are caught each year, or information on the countries where these spouses are being deported to, if any. It would also be beneficial to know whether the issue is gendered. It is evident that mail-order brides and arranged marriages are focused on women, but the literature does not state what proportion of those who are paying large sums of money or misrepresenting documents are men or women, either on the side of the sponsor or the sponsored spouse (Belleau, 2003). 
In the above section, detection and consequences were discussed; however there is a gap in the literature that it does not clearly identify how one is deported or the process of distributing fines and notices of deportation. By discussing the threat of deportation and charges, it does not present a clear depiction of how seriously these crimes are taken, and whether these consequences are enough to deter the act of fraud. If the consequences were quite extreme, it may lead one to consider if fraudulent marriage is an easier route to immigration than the current formal points system. The Canadian immigration system prides itself on the points-based system; however, with further reference to gender relations, it would be worth considering whether fraudulent marriage is a gendered act. Is the point-system is too rigid or discriminatory to allow some people (especially women) to be given entry to Canada, and if so, is the fraudulent marriage route the most efficient means of gaining entry to Canada?

The literature was also limited in terms of policy recommendations for the future. The policy clearly indicates that the marital probation period is only required for those without children; it would be interesting to uncover whether women would become pregnant to both have an "anchor baby" to keep ties to the country and to also become exempt from the clause. This would further implicate the policy, and ultimately be unfavourable to deterring marriage fraud.

\section{CHAPTER 3: Theoretical Framework}

In this section, I will outline two theories used to frame the understanding of the policies implemented to deter marriage fraud. Firstly, I will discuss Foucault's theory of biopower. This theory was chosen specifically as it represents the direct relationship between government and citizens in terms of migration. Foucault is able to outline the ways in which the power upheld by government through things such as the law is able to control the lives of many people which 
includes marriage. Secondly, I will discuss Said's theory of orientalism. This theory was chosen to supplement biopower because it provides an explanation as to why government decisions or laws are made in a certain way. Orientalism explains the differences between the West and East, and how people such as those being sponsored are subject to meet Western cultural norms.

\section{Foucault: Biopower}

The primary theoretical framework chosen to critically analyze fraudulent marriages and immigration is biopower. Biopower is a term coined by Michel Foucault to understand the relationship of power between the state and citizens. Another theory which will be discussed in more detail later is orientalism by Said which explains the concept of defining the "foreigner." Foucault outlines that there are regulatory controls of the population on phenomena such as birthrate, longevity, public health, housing and migration (Foucault, 1978). Foucault discusses this regulatory control as taking place through the subjugation of bodies and control of populations as biopower. The regulatory body of power can be understood as the government and state which dictate laws and rules as to how a population is controlled. For the purposes of immigration, it is evident that all regulatory bodies of government have control over who is "allowed" and worthy of entering a country such as Canada or the United Kingdom (Nadesa, 2008). By allowing a government or state to create laws surrounding the migration of people, it is evident that biopower exists by controlling the physical body and life of a person.

To further understand the scope of biopower, Foucault discusses multiple racialized groups as threatening homogenized power by stating: "race is inscribed as the basic mechanism of power, as it is exercised in modern states" (Foucault, 1975). Foucault outlines the importance of race distinctions and the influence of biopolitical practices which may be implemented to 
maintain a homogenous identity. Through immigration policies targeting racialized nations, the presence of biopower becomes evident. By linking power to race, the immigration policies related to foreign marriages and sponsored spouses from other countries depict a possible racialized undertone. Critiques to Foucault's understanding of race include the ignorance of "mixed-race" and defining the members of "racialized" or "oppressed" groups (Christensen, 2004). Although the definitions of these complex terms can be debated, the relation to biopower and controlled immigration as an avenue toward constructing race relations, is still prominent because it focuses on the country of origin when administering immigration status to spouses. Although Christensen (2004) writes in an American context, Western values can still be applied; any country which does not share "Western values" can be considered as "foreign" or the "other" which will be further discussed later.

The exercise of power over people and their lives is constituted as biopower. The regulation through the creation and monitoring of a population can also produce discourse of a desired society, which is where Foucault discusses the power of knowledge through government (Foucault, 1978). Foucault explains that by obtaining knowledge or controlling information, the government and state can effectively regulate who is "allowed" and who may seem threatening based on qualities such as race. This "desired society" is clearly formed through immigration policy. Although the government cannot control who is born within the country, they can control who will immigrate into the country and redefine their society. In this sense, biopower can be viewed as a control to a specific population.

Through the utilization of institutions such as the state, Foucault argues that biopower is a method created to ensure power maintenance through tactics such as immigration policies. Foucault discusses this process as a technique to have power at every level of the social body and 
to utilize this power through institutions such as family and collective bodies (Foucault, 1978). Through considering the institution of family, the government is able to decide whether a marriage between two people from different countries is deemed legitimate or genuine, and whether the sponsored spouse is able to enter the desired country. This form of power reinforces the maintenance of the "desired society" and blatantly regulates the lives of citizens.

\section{Said: Orientalism and Othering}

To supplement Foucault's theory of biopower and the "desired society," the theory of "orientalism" is relevant. Edward W. Said explains the concept of orientalism as a way to understand the cultural assumptions of the West onto the East (Said, 1978). This theory explains how Eurocentric views can be imposed on other cultures and can therefore act as justifications for criticisms. Said's discussion of the West versus East is a reinforcement of understanding the "foreigner" as there is a clear distinction made. Said explains that the West often perceives other cultures as being the "other" (Said, 1978). By identifying the "foreigner," Said also raises the concept of making any culture other than the West as the "other" and is therefore different and perceived as inferior (Said, 1978). When considering this theory, it is evident that Western countries such as Canada and the United Kingdom may impose orientalist practices when creating laws or interpreting other cultural practices. Relating Said back to biopower, it can be seen that the power implemented by the West through immigration policies are products of orientalism which “others” any other country which does not share Western values.

As discussed, biopower is a form of control over the body, however it can be argued that biopower is a necessary measure to ensure security and effectively manage a large population. For the purpose of this paper, biopower will refer to Foucault's specific understanding that 
biopower is a mechanism through which the basic socially constructed features of the humans, such as race, are an object of political strategy and power (Foucault, 1977). This will be supplemented by the understanding of orientalism presented by Said. The act of othering the "foreigner" reinforces the power of Western practices upon different countries and people (Said, 1978). This understanding recognizes that governments and states are able to control the basic functions of humans through migration, and in this case have the power to deem genuine and fraudulent marriages.

\section{CHAPTER 4: Research Methods}

The intention of this research is to analyze and critically assess the policies surrounding fraudulent marriages and their affects on people and the state. For the purposes of this paper, a qualitative and critical discourse analysis is used as a method of research. As discussed by Archer and Berdahl (2011), qualitative research can be difficult, however this method allows for the most exploratory route to complete the study. This approach will focus on the quality of the policy and determine the social implications using the specific documents and sources from the United Kingdom and Canada. The documents being used are official transcripts from the Parliament in both the United Kingdom and Canada. In addition to the transcripts and other government published documents, national news sources such as the Canadian Broadcasting Corporation, National Post, Globe and Mail, The Star, British Broadcasting Corporation, Guardian, Observer, Financial Times, and The Economist are researched and consulted. These sources have been chosen specifically as they are well-known in Canada the United Kingdom. Although each source will have a different perspective, it is not the intent to analyze the different ideologies of the sources considered "mainstream media." The ideological assessment of these 
sources would be helpful for future researchers to discuss, to understand their political motivations.

\section{Critical Discourse Analysis (CDA)}

Critical discourse analysis ( CDA) is described as an inquisitive approach to "examining the aspects of the structure and function of language in use" This definition focuses on the importance of conceptualizing language and how terminology or discourse can provide a tone and shape opinions for a specific audience (Sunakawa, 2008). In this paper, I will outline specific themes gathered from the sources mentioned above. To locate the relevant articles, I have searched the online databases available with all of the relevant terminology relating to fraudulent marriages and probationary residence policies. Some of the terms include: bad-faith relationships, forced marriage, marriage of convenience, fraudulent marriage, sham marriage, and conditional residency. After this was complete, I developed an outline of the trends which will be discussed below. By using CDA, I am able to assess the general tones towards fraudulent marriage and question whether the media and literary coverage provided is creating a biased narrative, or whether there is a neutral standpoint.

Although a quantitative approach would enhance the breadth of the study, developing empirical research would not help to understand the cultural and emotional consequences involved for those involved in marriages that can be defined as fraudulent. To critically assess the social consequences, CDA is necessary. However, this is not to exclude the use of other data provided by the Canadian government. Statistics will be used to further develop and understand the number of reported fraudulent cases and the understanding of international marriage and sponsorship within Canada. There is a lack of empirical data surrounding marriage fraud, and of 
statistics on which countries or gender is most at risk. This paper will use the scant available information to work toward an understanding of why the policies were implemented, and their affects on immigration and on individuals sponsoring spouses from other countries.

\section{Researcher Self-Disclosure}

As a Canadian-born middle-class and racialized woman studying at Ryerson University, my experiences with marriage fraud are limited. Due to my South-Asian background, I am able to understand the cultural discourse surrounding arranged marriages and realize that the practices of South Asians may not be understood by Western cultures which have influenced my interest in this topic of study. In addition, my recent encounters with a person sponsoring a spouse from outside of Canada, have made me interested in the risks of marriage fraud and how the government is implementing policies that are meant to protect its citizens. It has also made me aware that there may be dire consequences for the spouse once s/he arrives in Canada. Rather than seeing my personal experiences as an influence to the study, it may be perceived as an unavoidable element to the interpretation of the study. My experiences are mirrored in fraudulent marriages as a current topic in the media. Although I am culturally aware of South Asian traditions, I do not have a wide understanding of all cultures or people that may be involved in marriage fraud. This topic can be sensitive as it addresses the global issues that cause people to commit marriage fraud in order to attain a "better life." I will keep this in mind throughout the study and will attempt not to criminalize or demean those who commit marriage fraud.

This study is not politically motivated or funded by a government/private organization. By being an independent researcher and using this study to complete my master's degree at a 
Canadian university it allows the study to be reviewed by other academics and increase the trustworthiness of the study.

\section{Strategy}

As mentioned above, this study will include critical discourse analysis. The main reason for this type of study to use CDA is to be analytical of the policies in terms of social power, abuse, dominance and inequality which can be reproduced through the new legislation. Although critical discourse analysis usually takes a position, the study will attempt to be impartial while being critical, and will attempt to understand the effects of the policies on people, rather than take an explicit side (Van Dijk, 1999). Due to the time constraint and limited access to information such as specific statistics and recent census data, CDA allows for a critical insight on the policy and is able to supplement this information with other forms of discourse such as media and news articles which provide real examples and cases. Given the opportunity, it would be helpful as a researcher to interview those who have experienced marriage fraud, or those who are currently sponsoring or living with their sponsored spouses to see how the policies have impacted their immigration experience. This type of research would be able to supplement the findings and enhance the breadth of the study, but is outside my current scope.

As discussed in the previous chapter, the theoretical framework will be biopower, which will further develop the study to engage with themes of power, governmentality, and political motivations (Foucault, 1977). CDA proves to be the most accessible and logical strategy as the aim of the study is to understand the implications of the policy for citizens and sponsored spouses, and will not require any new forms of data collection. If the duration of the study was 
longer, it would be possible to conduct a more in depth collection of statistics and interviews which would be able to reinforce the study's objectives.

\section{Scope}

This study specifically focuses on the newly implemented immigration policy which requires the sponsored spouse to live and be under the financial and legal responsibility of the citizen who is sponsoring them as a measure to act against marriage fraud. I will use literature available from Canada and the United Kingdom because the UK has a similar policy in place. Along with the policy being similar, the laws, culture and general political stance is similar to Canada which makes the comparison understandable and feasible for the purpose of this study. Although other countries such as the United States and Australia also face similar marriage fraud issues, analysing each country's policy and comparing it to Canada would not necessarily be beneficial to this study, as the UK was among the first countries to implement this concept and influence other countries. The study focuses on Canada as a whole as the policy is federal which allows for the focus to be on a national scale. The policies for the UK and Canada were both implemented in 2012, which will narrow the time frame of research to five years before 2012 in order to analyse the trends that caused these policies and regulations to be implemented. Although the events pre-2007 will also be relevant, due to the time restriction and length of the paper, the immediate five years pre-policy implementation will analysed as the most significant events leading to the new policies.

\section{Setting and Sample}

The study is conducted from Toronto, Canada as it is where Ryerson University is located. The content of the study is obtained from multiple sources in Canada and the United 
Kingdom, using online databases. The sample for CDA consists of official transcripts from the Parliament in both the United Kingdom and Canada via Hansard; other government published documents such as websites/videos or interviews; and national news sources such as the Canadian Broadcasting Corporation, National Post, Globe and Mail, The Star, British Broadcasting Corporation, Guardian, Observer, Financial Times, and The Economist.

\section{Data Collection}

The data collection begins with government resources from both Canada and the United Kingdom that describe the visa and marriage policies related to spousal sponsorship. These are publically available official websites and documents provided by the government. Using the United Kingdom Border Agency, Canadian Border Services Agency (CBSA), and Citizenship and Immigration Canada (CIC), it ensures the quality of the sources. The policy for the UK is listed under "Marriage and Civil Partnerships" and was listed as of July 2012. The Canadian policy is listed through a press release on October, 2012, and also through Citizenship and Immigration Canada's website under the "Immigration and Refugee Protection Act" which was updated on October 25, 2012.

Other government data sources include Statistics Canada to provide further information on the number of sponsored spouses. Although the statistics provided do not separate each category into those such as sponsored spouses, they are broken down into "family class" which will aid in deciphering the data. Using government data prevents bias and does not aggregate the data, but rather represents Canada as a whole opposed to isolating specific regions. The discourse surrounding the topic, other than policies will be found through scholarly journals that discuss issues such as fraudulent marriage and the social implications of immigrant spouses. The 
research will also expand to understand the conceptualization of marriage in a Western context and how it is represented within political and media discourse. The research includes the search of all terms discussed in the literature review, as well as those from countries such as USA, Australia, UK and Canada as the academic discourse directly related to fraudulent marriage is limited.

Additionally, newspaper sources and other media sources such as the Canadian Broadcasting Corporation, National Post, Globe and Mail, The Star, British Broadcasting Corporation, Guardian, Observer, Financial Times, and The Economist are used to collect information on the recent political changes as well as social responses to the probationary period. The data collection attempts to include multiple news sources to ensure a variety of perspectives, however, the focus remains on national sources. In Canada, most of the focus will come from news in major cities such as Toronto, Montreal and Vancouver as they seem to have the most prevalent and recent information which most likely will have to do with their large immigrant populations. Another weakness in the collection of media sources is that there is no specific number from each of the sources. Out of every source, a minimum of three articles were collected, whereas some sources could have ten or more relevant articles. Due to the fact that the discussion and policies surrounding fraudulent marriages are fairly recent, there were not an overwhelming number of articles to read. In conducting the research, I would search each media source's website for all of the relevant terminology as discussed above. After these articles were collected, I continued to only include articles over 200 words as they seemed to have the most breadth which would also reference anecdotes or quotes from parliamentary sources. By using articles over 200 words, it gave more scope to delve into details and to possibly present an opinion to which I would be able to react through the means of analysis and critique. 
The strength of this data collection process allows for a wide understanding of both academic, government and media sources to understand the topic of fraudulent marriage. Other strengths of this data collection allow the researcher to sift through all irrelevant articles and irrelevant data without having to compile results and analyse sources such as surveys. Some shortcomings of this data collection are that it concentrates on major cities and may not include sufficient anecdotal occurrences and other details. Articles that include anecdotes have preselected quotes to use, which does not allow the researcher to analyze the entire interview and choose their own quotes.

Due to time concerns, I was unable to fully assess other policies such as those in the United States and Australia who have similar probationary residencies. I was also unable to include more sources from the UK and Canada which may discuss at least one case from each major region as opposed to discussing one particular city. Due to budgetary concerns, the collections of particular statistics were not made available to me as a student which limited the results to those available to the public.

\section{Data Organization}

The organization of the data includes a list of recurring themes (Attride-Stirling, 2001) from both Canadian and British sources. Once the themes were collected, they were organized by date, and country. This allows for a clear indication of where recurring themes occurred and if they progressed during legislative changes.

As with most qualitative research, reaching a point of saturation can be difficult as there are always new angles and perspectives which can be incorporated. "Saturation" as defined by Morse as "data adequacy" among research (Morse, 1995). By this, Morse operationalizes the 
term as collecting data until no new information is obtained. While there is no specific way to fully reach saturation, Morse indicates that qualitative research values variation over quantity (Morse, 1995). As mentioned above, developing a highly comprehensive list of themes, terms, and angles which need to be considered is crucial to ensuring my research is fully tailored and focused for this study. Once my research does not develop any "new" information, I use this to understand saturation.

\section{Data Analysis}

Analyzing qualitative data can be difficult because it cannot be reduced to something definite like quantitative data. Besides using personal analytical tools, there was no software used to help with the analysis of qualitative data for this study. In terms of analyzing statistics, Ryerson University's librarians and data specialists were able to aid in deciphering and obtaining relevant statistics pertaining to the study.

Through the theoretical framework of biopower, the analysis of information will be geared towards understanding the role of the state. The critical analysis is thus grounded by this theory and the ways it is present in fraudulent marriage and immigration practices. The analysis stems out of careful and thoughtful approaches to understand the effects of new policies surrounding marriage fraud. Although the study is conducted from a Canadian point of view, the analysis of other "Western" countries will aid in understanding the global response and motivations to marriage fraud.

\section{CHAPTER 5: Findings and Analysis}

To recall, the purpose of this research is to outline the ways the new policy on fraudulent marriages, implemented by the Canadian government, will affect spouses and partners. By 
considering the multiple facets of a relationships and cultural expectations, in the first section, I will discuss the shortcomings of the policy. The policy is directly related to protecting borders by creating legal consequences for those sponsoring spouses in different countries as well as for those being sponsored. I will then analyze the media sources such as news coverage from both the UK and Canada. The analysis will include themes of acceptability which discusses how “accepting" policies are for sponsors. The other themes are crime and control, economic benefits, and victimization. This chapter will conclude with an analysis of similarities noticed from both countries and it will conclude with an analysis of the available statistics for both Canada and the United Kingdom.

\section{Legislative and Policy Depictions}

Both Canadian and UK laws outline the importance of being in a "genuine" or "legitimate" relationship. The United Kingdom Border Agency (UKBA) outlines that an applicant and their spouse must provide evidence that they are in a genuine and subsisting relationship (United Kingdom Border Agency, 2012). As discussed earlier, the definition of "legitimate" can be fluid across many different cultures and therefore creates a standard of how one's relationship should be measured. The UKBA explains that caseworkers are exposed to religious and cultural practices which shape different relationships and this includes being sensitive to practices such as arranged marriages where the couple may have spent little to no time together before the marriage (United Kingdom Border Agency, 2012). However, in contradiction to this statement, the UKBA further indicates that caseworkers must take into account "normal practices" such as evidence of pre-marital cohabitation, joint living arrangements, household bills to be in a joint name/account, or presence of children when considering foreign marriages (United Kingdom Border Agency, 2012). It is evident, as will be 
elaborated below, that the definition of a "genuine" relationship is shaped by Western hegemonic practices, and may impose scrutiny on relationships which do not share these "normal practices."

In defining a fraudulent marriage, the UKBA outlines a long list of factors that may determine a fraudulent marriage. Some of the guidelines include: having the marriage take place in the UK as opposed to abroad; a statement referring to the marriage as fraudulent; the applicant or sponsor publicly stating they have been forced into marriage; few to no people at a marriage ceremony; inability to provide accurate details about each other; and money exchanges (besides a dowry). Additional details in the guideline for detection of fraudulent marriages make reference to checking if the applicant previously applied to remain in the UK and was refused under a different category; or there is evidence of fraud from a third party such as the police, social services, registration service or minister of religion. The list also considers the capacity to consent to a marriage/relationship. The details for this include whether the applicant or sponsored spouse is able to mentally/physically consent through a social service assessment, and this also includes obtaining evidence of whether there were restrictions placed on the applicant/sponsored spouse such as being kept at home by the family (United Kingdom Border Agency, 2012). These considerations are quite important as they appear to protect both parties involved, however, it also quite evident there are many restrictions and a large measure of subjectivity to each of the guidelines. Each of the guidelines is attached to a disclaimer that indicates that a caseworker is able to apply their own judgement before they make any decisions in the case.

To note, unlike in the UK, the Canadian government has not officially defined "legitimate" or "genuine" terms for a marital relationship. This lack of definition allows for Canadian immigration officers to use their own interpretation and biases to decide whether a 
relationship is in fact "genuine." As CIC has outlined, there are immigration officers who are trained to understand multiple cultural definitions of "legitimate" relationships (Citizenship and Immigration Canada, 2010).

In the cases of both Canada and the UK, it is evident that there are many different ways to interpret "genuine" or "legitimate" marriages. Although the United Kingdom has outlined some of their guidelines, it is evident that both immigration officers and caseworkers have the most power in determining what constitutes a fraudulent marriage. By giving this responsibility to those employed by the government is a clear indication of biopower. As previously mentioned, the state is able to exercise power over people through laws and regulations (Foucault,1978). The regulation of determining a "genuine" or "legitimate" relationship allows the state to have control over which people are able to legally be together based solely on the fact that they are from another country. This type of control reinforces Foucault's notion of using migration controls as a political strategy of power (Foucault, 1978). By controlling who is welcomed into the country, the state is able to define a specific population that could be motivated by factors such as economics, or by determinants of race or gender. As it will be discussed, the UK has implemented a financial requirement for future sponsored spouses which reinforces the focus on economic gain and an attraction for a specific "wealthy" population.

The parliamentary debates in the United Kingdom also manifest concerns related to fraudulent marriage. The transcript states:

The Government recognises the risk that sham marriages, arranged primarily for immigration purposes, pose to our immigration system and their links to wider criminality, such as fraud and benefit abuse. We are working closely with our partners across government and with local registration services and the Anglican Church, to identify and tackle sham marriages at the earliest point... Under section 24 of the Immigration and Asylum Act 1999 registrars are required to report to the Home Office 
any persons they have reasonable grounds to suspect [two people] are entering into a marriage arranged primarily for immigration purposes. Section 24 reports are investigated and, where appropriate, action is taken. (Parliament UK, 2013)

This discussion clearly indicates the worry over those who are potentially taking advantage of government assistance and benefits. The attempt to halt marriage fraud requires deep investigations and, as quoted above "reasonable grounds to suspect" a fraudulent marriage. Once the investigation or suspicion is validated, the consequences as listed under Section 24 include deportation, imprisonment and/or a fine (Parliament UK, 2013).

Besides the criminal implications, the probation period in the United Kingdom ensures that sponsored spouses cannot apply for settlement before being with their spouse for two years. Although there are exceptions such as one spouse working or studying away from the home, it is expected that the spouses live together and share details of their lives which will be assessed by immigration caseworkers upon their application for settlement (United Kingdom Border Agency, 2012).

Canada has similarly attacked the concept for foreign nationals marrying Canadian citizens (or permanent residents) to gain entry into Canada (Citizenship and Immigration Canada, 2012). In order to detect marriage fraud, CIC has stated:

Effective October 25, 2012, sponsored spouses or partners must now live together in a legitimate relationship with their sponsor for two years from the day they receive permanent residence status in Canada. The new regulations apply to spouses or partners in a relationship of two years or less and who have no children in common with their sponsor at the time they submit their sponsorship application. The spouse or partner must live in a legitimate relationship with their sponsor for two years from the day on which they receive their permanent resident status in Canada. The status of the sponsored spouse or partner may be revoked if they do not remain in the relationship. (Citizenship and Immigration Canada, 2012) 
The requirement to live with the spouse is an obvious attempt to deter fraudulent marriages to Canadian citizens who may either be aware or unaware of the fraud. It is stated by CIC that this policy is inspired by the United Kingdom, United States and Australian policies which include conditional permanent residency (Citizenship and Immigration Canada, 2012). However, the Canadian regulation specifically mentions spouses without children at the time of their application, as opposed to the policy in United Kingdom. Although it is not discussed as to why this is an important concern, it may be attributed to the commitment to family reunification. This presents the understanding that shared children amongst spouses would demonstrate a specific commitment to each other that may not otherwise be present in fraudulent marriages.

The parliamentary debates in Canada include the impacts of marriage fraud and include the fact that marriage fraud is highly organized and can involve payments as high as $\$ 50,000$ to the sponsor (Parliament of Canada, 2012). Another issue which is mentioned in the debates is that applicants may memorize a specific officer's interview questions and then relay or post them for other people to see and prepare for when they are interviewed by immigration officers (Parliament of Canada, 2012). By recognizing the lengths that people are willing to go to in order to obtain access to Canada presents an important consideration for the Canadian government.

By increasing border security in relation to fraudulent marriages, the Government of Canada has outlined that there will be extensive measures which will be enforced in order to effectively prevent marriage fraud. The parliamentary debates include references to training all immigration officers to identify fraud. As previously discussed, although the immigration officers may be trained to detect fraud, there may be a chance of personal prejudice or the inability to fully understand the nature of relationship or applicants' culture, and therefore the sponsor and their spouse may be unable to meet that specific officer's standards. 
One section of the parliamentary debates uses New Delhi, India as an example of how and where fraudulent marriages can occur. As of 2011, the visa office in New Delhi has an antifraud unit which includes one CBSA anti-fraud officer, and five local staff members (Parliament of Canada, 2012) responsible for investigations which include telephone verifications, document verifications, and site visits. This process has resulted in the refusal of $15 \%$ of sponsored spouses during the first nine months of 2011 (Parliament of Canada, 2012). Although it is noted that the New Delhi office identified a significant number of fraudulent cases, there are no specific numbers or quantitative measures to determine the total number of applicants. There is also a mention of many applicants who see "consultants" regarding ways to submit fraudulent documents as a method of clearing CBSA and obtaining access to Canada (Parliament of Canada, 2012). In all cases, once the spouse or partner has arrived in Canada, there is opportunity for CIC to investigate the marriage through system checks, open-source (online) research, a review of the physical file, or interviews. The CBSA can further this investigation by performing additional acts such as house visits, and surveillance (Government of Canada, 2012).

Although the Canadian legislative debates and policies attempt to understand marriage fraud and seem to strive to ensure the importance of family reunification, it is noticeable that there is a large influence on detecting fraudulent marriages after the couple has arrived in Canada. By considering biopower, it can be noticed that there is a connection between the state enforcing power over the sponsored spouses. Foucault explains that through the collection of knowledge, the government can effectively regulate who is "allowed" in (Foucault, 1976). In the case of CBSA, by gathering information through surveillance and performing visits, they are likely to obtain the information they need to make a decision of whether the relationship is "legitimate." Although state surveillance is needed to ensure that crimes such as fraud can be 
detected, it is unclear as to what extent the government is performing this surveillance and at which point (if any), they are satisfied or dissatisfied with their findings. This provides deeper insight as to how the state is reinforcing biopower through the laws created by the government to possibly serve their needs (Foucault, 1977).

To further develop the concept of biopower in terms of regulating migration and population, in the United Kingdom, in addition to the probationary period there is a financial requirement which states that when you apply to come to, or stay in the UK as the partner of a British citizen, a person settled in the UK (permanent resident), or a person in the UK with refugee leave or humanitarian protection, must have an income of at least $£ 18,600$ (UK Border Agency, 2013). The equivalent today is approximately Cdn $\$ 30,120$ (Reuters, 2013). This financial requirement alters if there are dependents (children) applying as well. Although it appears logical to ensure the applicant has a salary and will be able to support themselves upon arrival, it is also necessary to question who is actually eligible with that salary. By creating a financial requirement for spousess abroad, it is obvious the United Kingdom is being extremely selective as to who is able to enter their borders regardless of their marital status. By understanding that not every person, including those in developing countries will be able to obtain a career that offers the equivalent of $£ 18,600$, it can be argued that this policy is racially and economically motivated and discriminatory. As both Canadian and UK policies state, the relationship between two people should be "genuine" and "legitimate" however it appears that this is only relevant within a specific economic parameter.

Canada has not implemented an economic rule for sponsoring spouses as of yet, however CIC has made it understood that when Canadian citizens or permanent residents sponsor their spouse, it is with the undertaking of a financial responsibility of three years (Government of 
Canada, 2013). Even if the relationship breaks down for any reason, the sponsor remains financially responsible for the spouse. This three year period also bars the sponsor from sponsoring possible subsequent spouses (Government of Canada, 2013). It is clear that the government is imposing many restrictions and responsibilities on those who are sponsoring spousess. The focus on finance, and threat of deportation are meant to reinforce Canada's commitment to end marriage fraud and to make Canadians and permanent residents think twice before sponsoring a spouse [or partner] from abroad as there are greater consequences (Government of Canada, 2013). The ability to deport someone and implement a three year financial responsibility for another person is another example of how biopower is operating through immigration. This type of regulation can be considered a form of subjugation as the government is creating a tie from one person to another solely on the basis of migration.

\section{Media Discourse}

In this section, I will analyze the news sources as discussed earlier. As discussed in the methodology, the critical discourse analysis developed themes across different media sources. I will analyze the most prevalent themes across British and Canadian news sources. I will begin with the United Kingdom, and then discuss Canadian media. The themes arising from the

analysis of UK media contents are: acceptability, crime and control, and economic benefits. The major theme arising from the analysis of Canadian media is victimization.

\section{Media Themes from UK}

Acceptability. In the United Kingdom, The Guardian and Observer present a strong case for the sponsors and those being sponsored. A common theme is "acceptability." Many of the articles question the motives of the government by asking: "When is it acceptable to imply limitations on British citizens when choosing to have a relationship with a non-European 
Economic Area national?" (Travis, 2012). In addition to this theme of "acceptability," The Guardian quotes UK Home Secretary Theresa May to demonstrate the overall tone of how the policy affects people:

But if they want to establish their family life in the UK, rather than overseas, then their spouse or partner must have a genuine attachment to the UK, be able to speak English, and integrate into our society, and they must not be a burden on the taxpayer. Families should be able to manage their own lives. If a British citizen or a person settled here cannot support their foreign spouse or partner they cannot expect the taxpayer to do it for them. (Travis, 2012)

This quote is indicative of the direction and aims of the new policies surrounding sponsored spouses. By including this quote, The Guardian critically assesses the state's involvement in relationships with those outside "acceptable" countries. This is also a reinforcement of the distinction between the "foreigner" and the "outsider" which emphasizes an orientalist ideology as discussed by Said (1978) as the way Western societies perceive the East. This understanding explains the ways the "foreigner" can be seen as different and thus not accepted into British society (Said, 1978). Although it is outside the scope of this paper, it is important to understand the role of transnationalism and how it affects the concept of "foreign."

The Economist (2011) presents an interesting article which questions the understanding of "acceptability." An article discussing international marriage maintains a critical perspective on new policies which make international marriages difficult and can be understood as "foreign spouses". The article questions whether a second-generation immigrant born in the United Kingdom marrying someone from their parents' home country is still worthy of being titled a "foreign spouse." By presenting this argument, The Economist (2011) questions the ethnic ties to their home countries and whether countries such as Canada and the United Kingdom are aware 
of these ties during the sponsorship process and how if any way does this influence those sponsoring spouses if they are considered "foreign".

Crime and control. Through the analysis of the British Broadcasting Corporation (BBC), there is most coverage on the discovering and scale of scams. The common reference is "crime and control." Although fraud is punishable by law, many of the articles published by the BBC discuss the operations of fraudulent marriages and the illegalities. The focus on "crime and control" also discusses the consequences (imprisonment or fines) for the organizers and participants. Examples of headlines regarding fraudulent marriages from the BBC include "Couple jailed for Hull sham marriage plot"; "Arrest warrant for chef convicted on sham marriages"; "Groom arrested in Liverpool 'sham marriage' to be deported"; "Sham marriage raids: Ten people arrested"; "Pakistani man arrested in Glasgow over 'sham marriage'". By simply viewing these headlines, it is evident that the theme of "crime and control" is prevalent. The main focus on convictions identifies the importance and directions of the news coverage. An article titled "Gretna sham wedding operation sees eight men arrested" quotes the Home Office immigration enforcement team as having indicated that: "Anyone in the UK illegally should 'take heed' of the latest operation. Expect to be caught by us and removed from the UK...We will not hesitate to act against those who mistakenly believe that they can abuse the immigration system" (BBC News, 2013).

In addition to outlining the possible criminality surrounding foreign spouses, the BBC cites legislation such as Article 8 which includes the right to a family life (BBC News, 2012). In this specific news report, there are subsections indicating "border failings" which include statements from human rights advocacy groups that indicate negative implications of the policy such as the separation of family. However, the main focus is placed on understanding the crimes 
of sponsoring a spouse as well as controlling future immigrants by "reinterpreting" Article 8 (BBC News, 2012). The reinterpretation of Article 8 can be interpreted as a form of biopower, as the current laws are made to appear too lenient, and therefore as not effectively controlling the population (Foucault,1978). By reinterpreting this article, there is opportunity for the laws to become more stringent and give the state more power over immigration practices and border control.

Economic benefits. A less prominent theme throughout the analysis of media sources is "economic benefits." This theme is most prevalent through sources such as the Financial Times and The Economist. The Financial Times published an article reviewing the minimum salary requirement for sponsored spouses in the UK. The articles include a deeper understanding of "proving financial viability" (Financial Times, 2013). An investigation of rules to provide financial proof includes presenting the values of stocks and shares worth over $£ 62,500$ if they are liquidated six months prior to the sponsor's application (Financial Times, 2013). By examining the financial aspect, the Financial Times (2013) recognizes the government's commitment to migration with a heavy focus on capital by stating that many business owners will be unwilling or unable to liquidate their assets in such a short period of time, especially if there is no guarantee that the application will be accepted. In addition to analyzing investments, the Financial Times (2013) also includes a social perspective that quotes the Migrants' Rights Network by stating: "Even families with considerable resources available to them had been prevented from living together in the UK. We hope government will agree to review this policy, to ensure that it stands up from an economic, as well as social, perspective". By providing a social insight, this financially-focused news source is able to predict the hardships and nuances 
within the sponsored spouse policies for the United Kingdom. An example to demonstrate the nuances is presented in the following manner:

The firm gave the example of an Australian national married to a British national, who is chief financial officer with a multinational company in Dubai. His UK earnings would be $£ 400,000$ a year, and the couple have property worth over $£ 3.5 \mathrm{~m}$ - but they have been unable to relocate to the UK. This is because his earnings overseas could not be considered and his wife is not employed nor does she intend or need to undertake employment in the UK. (Financial Times, 2013).

This example presents the difficulties with proving the fraudulence of a marriage and effectively demonstrates how intricate the policies are against foreign spouses regardless of the funds available. This is a direct link to biopower on the ability to unite foreign spouses through laws and regulating who is "allowed" based on financial means as well as country of origin (Foucault, 1977).

\section{Media Themes from Canada}

Victimization. In Canada, the Canadian Broadcasting Corporation (CBC) plays a similar role as the $\mathrm{BBC}$ by focusing on the cost of crime, but in contrast to the $\mathrm{BBC}$, Canadian content can more readily be described as having the logic of victimization. Although Canadian media does cover themes such as crime and control, it is almost always paired with the understanding of the "victim." By discussing victimization, it presents an alternate perspective which is unique to Canadian media, but is not limited to exempting the themes located in UK media.

The CBC reported on a number of people who are in the process of sponsoring their spouses from other countries or have been victim to fraudulent marriage. The coverage is titled "True Love or Marriage Fraud? The Price of Heartache" (Canadian Broadcasting Company, 2011). This states that at the time approximately one thousand cases of fraudulent marriages 
were reported annually (Canadian Broadcasting Company, 2011). This is one of many Canadian articles that refer to the sponsor as a victim, which presents the theme of "victimization." This victimization is discussed as sponsors who have been "duped" by their sponsored spouses by being used for immigration purposes. Although this article/documentary was released before the implementation of the conditional residency, the discussion of victimization is quite relevant. By articles such as these discussing sponsors as "victims," it is often followed by a cry to the government to protect its citizens. The CBC quotes the documentary's director as having said: "Marriage fraud victims are penalized twice. Firstly by the fraudsters that cheat and deceive them and then by the government that forces the victims to pay back any assistance that these fraudulent spouses collect from the government" (Canadian Broadcasting Company, 2011). This identifies the focus on the sponsor, and recognizes that their love and trust in a relationship should not be financially penalized. The National Post and The Star present a similar view by recognizing those who have experienced marriage fraud as victims through titles such as "Marriage to Cuban leaves bride broken hearted - and broke," and "From Cuba, yet another broken heart." (Mehta, 2013).

The discussion of sponsored spouses being victims upon arrival is barely present in Canada, nor is it evident in the UK. This discussion is necessary, but only seems to appear in academic journal articles and upon the mention of forced marriage. Forced marriage is defined by the Canadian government as the following:

One in which one or both people do not or cannot consent to the marriage and where pressure or abuse is used to force one or both people to marry against their will. Forced marriage also overlaps with child marriage because children are not considered capable of making an informed decision (Government of Canada, 2013). 
The discussion of forced marriage mainly surrounds cultural expectations, and is considered illegal unlike arranged marriages where both parties should consent. The National Post reports one story where a sponsored spouse claimed to be abused by his wife which is why he left her twenty-nine days after his arrival in Canada (Page, 2012). This specific case is quite detailed as there is mention of the sponsored spouse having children in his home country, as well as engaging in other romances while in Canada. The National Post presents a story of skepticism and frames the sponsored spouse as criminal opposed to a victim. The importance of investigating whether there are more victims of abuse upon arrival is discussed by the Globe and Mail as recognition of policy created by the Government of Canada. The Globe and Mail quotes CIC Minister Kenney:

The two-year probationary period won't apply in cases where evidence of abuse or neglect exists, If someone is mistreated during their first two years in Canada, they will be expected to report the abuse to immigration authorities so they can investigate [the claim].We will do the assessment and if it's a bona fide case of abuse we will ensure they are not penalized. (Mackrael, 2013)

This recognition is important to the development of the legislation, however, similarly to current domestic abuse cases, the reporting of marriage fraud can be quite low. Further, the new immigrant may not speak the language or be aware of how to file a report and prove the abuse (Komiotis, 2012). Komiotis (2012) recognizes that the conditional residency puts all sponsored spouses in the position of being threatened with deportation for two years. Conditional residency also places power in the hands of the sponsor because they are able to call authorities at any time and report the marriage as fraudulent which may lead to deportation (Komiotis, 2012). By considering biopower, it can be understood that in this situation, the sponsor and the government would hold biopower over the sponsored spouse. Being able to threaten the removal of a person from Canada or any country with addition of abuse demonstrates biopower on a macro and micro 
level for sponsored spouses (Foucault, 1977). In sum, it puts the rights and powers of the "insider/citizen" ahead of the "foreigner/outsider" as indicated earlier Said (1978). His focus on citizenship and the "insider" further demonstrates how countries such as the UK and Canada create exclusions via citizenship and immigration.

\section{Trends in Reporting for UK and Canada}

Outside of thematic analysis, noticeable trends in reporting are evident in the articles and news reports of the different media. One common trend is that most of the articles in Canada and the UK listed the country or general geographic area of origin for the sponsored spouse. While reporting the source country may be part of the journalistic process, it also specifically creates the "foreigner" and potentially stigmatizes people from that specific country. Some articles as mentioned above would even state the country's name in the title. This reinforcement of the "other" effectively displays the media attention on who the foreigner is specifically and criminalizes an ethnicity (Said, 1978).

Along with listing the country of origin, most articles listed the gender of the sponsored spouse. As noted, there are no available statistics as to how many men or women were sponsored as spouses in Canada or the United Kingdom. Gender plays an important aspect in uncovering who is involved and "victimized." Many of the articles reported women as Canadians being victimized by men from other countries. The reasoning for women being most prevalent in the media sources could simply be because they are more likely to speak out or that they are in fact sponsoring more than men. If the data became available, it would be necessary to analyze if and why one gender is sponsoring more than the other. It would also be relevant to understand whether one gender experienced a higher rate of fraudulent marriages in terms of sponsorship. 
This information could potentially lead to more insight or awareness on the issue. Another reason as to why a gender analysis is important regarding fraudulent marriages through sponsorship is to compare with other practices such as mail-order brides and whether there is similar treatment for these spouses based on gender and how this impacts Canadian regulations on sponsorship (Belleau, 2003). To further develop the conversation of gender, it is worth considering why fraudulent marriages are gendered. If they are most likely happening to bring women fraudulently into the country, a re-assessment of immigration policy such as Canada's point system may need to be considered as it is possible many of these people cannot immigrate legally due to the existing criteria which includes points for education, language knowledge, and financial stability.

\section{Statistical Findings}

The quantitative research available regarding fraudulent marriages in Canada is quite limited. However, there are many sources which do outline statistics relating to marriage and immigration. In this section, I will mainly focus on the Canadian statistics available and analyze

the information and how it pertains to those trying to sponsor their spouses. In analyzing statistics between 2002 and 2011, there was a peak of 5,767 sponsored spouses in Canada for 2006 (Statistics Canada, 2012). This number steadily decreased in 2011 to a total of 4,311 (Statistics Canada, 2012). While the statistical sources do not offer an explanation as to why the numbers decreased, the discourse suggests that there may have been more stringent rules to accepting foreign spouses in Canada. CBSA reported that in 2011, 104 people were deported from Canada for misrepresentation (Canadian Border Services Agency, 2012). CBSA also reported that between 2008 and 2010, they received approximately 200 leads on possible marriage fraud cases from multiple sources and opened thirty-nine investigations (CBC News, 
2011), though the outcomes of these investigations are unknown. Further to the analysis, it is important to recognize that the policies regarding migration surveillance and racialization may be outcomes of the $9 / 11$ terrorist attacks. Although these specific developments will not be discussed in this thesis, it is important to understand the shift in border security.

Citizenship and Immigration Canada released a report in 2012 stating that approximately 39,800 off-shore and 6,500 Canadian immigration applications for spouses were processed in 2010. Of these, $16 \%$ were rejected mainly due to bad-faith relationships as well as ineligibility based on medical, security and criminality concerns (Canadian Border Services Agency, 2012), but there are no details on the numbers pertaining to each situation. These statistics demonstrate the commitment to detecting fraudulent marriages in Canada. Although the statistics are not publicly available, it would be helpful to identify the source countries or geographic areas for most of the fraudulent marriages, in contrast to the unreliable media reports. It would also be useful to do follow-ups of the suspicious cases to see if in fact the sponsor and their spouse remained together. Understanding that this may take an extensive amount of time and money, it seems that if the government is making fraud detection a priority, more research needs to be done.

Similarly to Canada, the UK Border Agency reported that approximately 500 operations targeted suspect marriages in 2012 (United Kingdom Border Agency, 2013). In 2010, 934 suspected fraudulent marriages were reported by registrars compared to 561 reported in 2009. The UK Border Agency has made it clear that all reports need to be investigated and that the focus on detecting fraudulent marriages will only increase (United Kingdom Border Agency, 2013). 
For future sponsors, this heavy surveillance could mean a much more difficult process to prove one's marriage and relationship. Revisiting Qayuum (2010), relationships such as arranged marriages will be highly criticized and be under a lot of scrutiny. This is most likely when couples have only been introduced over the phone, or through online video-chats (Qayyum, 2010). Without a clear understanding of all cultures, it may be easy for one illegitimate couple to present all of the "normal" documents to pass immigration, while the legitimate marriages which simply do not have enough substantial evidence may be rejected. This is possible especially if immigration officers feel the need to meet a quota, or bear specific biases. The statistics presented suggest that the strive for a "desired society" is reinforced through immigration policies (Foucault, 1977). By analysing the statistics from United Kingdom and Canada, there appears to be a relationship between borders, foreign nationals and laws to deter "foreign" marriages. The reference to controlling foreign marriages is a clear indication of how Foucault's theory of biopower and Said's theory of othering are represented. By placing boundaries on the "foreigner," through policies related to marriage fraud, it appears that the government is creating laws and policies to control and allow a "desired population." The guidelines to these laws are specifically excluding racialized groups and people with lower incomes which therefore creates the "other."

\section{CHAPTER 6: Conclusion}

In conclusion, marriage fraud is evidently becoming a high priority for governments in Western societies such as Canada and the United Kingdom. To recall, marriage fraud is defined in Canada as "relationships that are not genuine and that were entered into primarily to obtain immigration status. This can happen when a couple pretends to be in a genuine relationship so that the sponsored partner can come to or stay in Canada. In some cases, the sponsor may be 
given a financial or other kind of benefit in exchange for the sponsorship" (Citizenship and Immigration Canada, 2010). By this definition, it is obvious that there is an importance of being in a country such as Canada or the United Kingdom regardless of the cost.

In 2012, Canada created a policy which subjects sponsored spouses to a conditional permanent residence which requires the spouse to cohabit in a "legitimate" relationship with their sponsor for a period of two years after receiving permanent residence status in Canada (Citizenship and Immigration Canada, 2012). During this two year period, the sponsor is also financially responsible for the spouse regardless if the marriage continues to exist. This response to fraudulent marriage is one which attempts to ensure that the sponsor remains responsible for the spouse they are sponsoring for a minimum of two years and attempts to deter any person from entering a fraudulent marriage.

To understand the policies and consequences surrounding fraudulent marriages, the theory of biopower is presented as a mechanism through which the basic biological features of the humans are an object of political strategy and power (Foucault, 1977). Biopower combined with Said's conceptual understanding of the "other" reinforces the discussion of how the government is controlling migration and subsequently creating a specific population which is othering racialized groups who are deemed as "foreign." By creating this distinction, governments are reinforcing the borders between countries regardless of their right to family reunification as advertized by both the United Kingdom and Canada.

The major distinction between the UK and Canada is that the UK is definitive in their understanding of legitimate marriage, and therefore their guidelines appear solidified and rigid. Unlike Canada, the definition of legitimacy for marriage is undefined and creates an opportunity 
for people to make their own conclusions. Other distinctions include the focus on crime and control for the UK, while Canada tends to focus on the victimization of the policies and how sponsors are being affected.

The victimization during fraudulent marriage is discussed as when sponsors have been "duped" by their sponsored spouses by being used for immigration purposes. To supplement this type of victimization, the discussion of abuse is also necessary. Although media articles do not thoroughly discuss to potential abuse for new spouses from foreign countries, academic journals effectively outline how women in particular can be subject to abusive relationships upon their arrival especially if they do not speak English and are subject to live with their new spouse. Canada's response to the potential abuse is for the spouses to report the abuse to authorities and that they will not be deported. Cultural marriage practices are also a large aspect in understanding fraudulent marriages. As discussed, practices such as arranged marriage leave little room for the ability to "prove a relationship" as is expected by immigration officers. Crossborder marriages are difficult to monitor due to the distance, which is why immigration officers as discussed by Citizenship and Immigration Canada are trained to understand cultural practices which may mean the spouses have only met through telephone conversations or on the day of the wedding.

A large discussion in this study surrounds the ability to prove a "legitimate" or "genuine" relationship. As discussed in many sections, the ability to prove a relationship is relative to one's conceptual understanding of a relationship. This paper has discussed the many ways some people may be able to fraudulently fulfill the definition of "legitimate" or "genuine" if their relationship fits Western standards. Those who apply with different cultural expectations may leave the 
government skeptical of the legitimacy of their relationship and therefore may not allow the spouse to obtain a visa.

It is my personal prediction that similarly to the United Kingdom, Canada will also implement a financial requirement when sponsoring spouses from different countries. I believe this will happen as a way to both deter the number of spousal applications being received, and to ensure that new immigrants (regardless of the relationship), will not take advantage of the social safety network provided in Canada. If Canada does implement this policy, the concerns would most likely be that those who truly have a legitimate relationship and are being sponsored for family reunification purposes may be denied. It is unrealistic for the government to assume that only those with a specific amount of money or those who have well-paying occupations are able to start a relationship. Another concern is that if fraudulent marriages are currently taking place and are including high payments for the sponsor, by implementing a financial requirement, it allows those with sufficient amounts of money to continue their current fraudulent practices and surpass the financial requirement. This is ironic, given the stated intent of economic deterrents. 


\section{Future research}

Unfortunately, due to time constraints there are many aspects of fraudulent marriages that I was unable to research further. I was unable to research how many new spouses were able to seek refuge from spousal abuse in Canada. Although this would be a difficult number to find, it would be beneficial to understand if this clause presented by the Canadian government is working. I would have also liked to investigate the tie to "home country" and find out how many sponsors were bringing spouses from their ethnic "home countries." This would be an important factor as it would provide context to the "foreigner." If the sponsor themselves ethnically identifies as something other than Canadian or British, is sponsoring someone from the home country truly "foreign?" The focus on gender is also important as it forces the government to reassess the inequalities of immigration policies and whether there is a heavy focus on one gender sponsoring the other for specific regions. A final point of research for the future would be to follow-up on sponsored spouses after the probationary period of two years. It would be useful to identify how many marriages remained intact, how many sponsors were "victims." It is my hope that all those who are in legitimate relationships be reunited with their spouses and the government is able to develop an effective strategy to distinguish the fraudulent cases from the legitimate, and to also understand the initial causes for people to resort to fraudulent marriages as a way to immigrate to Canada. 


\section{BIBLIOGRAPHY}

Archer, K., \& Berdahl, L. (2011). Explorations: Conducting Empirical Research in Canadian Political Science. Oxford University Press.

Attride-Stirling. (2001). Thematic Networks: An analytic tool for qualitative research. SAGE Publocations: Qualitative Research, 385-405.

Aulakh, R. (2010, July 16). Fastest way to get to Canada - marriage. Toronto, Ontario, Canada.

BBC News. (2012, June 11). Theresa May to give judges new deportation guidance. Retrieved from BBC News - UK Politics: http://www.bbc.co.uk/news/uk-politics-18384543

BBC News. (2013, July 24). Gretna sham wedding operation sees eight men arrested. Retrieved from BBC News: http://www.bbc.co.uk/news/uk-scotland-south-scotland-23432385

Belleau, M.-C. (2003). Mail-order brides and Canadian immigration policy. Canadian Woman Studies, 94-103.

Blumer, H. (1973). A Note on Symbolic Interactionism. American Sociological Association, 797-198.

Bosker, B. (2010, October 14). U.S. Government Exploits Our Facebook 'Narcissism' To Detect Fraud, Fake Marriages. New York City, New York, United States.

Canadian Border Services Agency. (2012, August 29). In response to: RCMP uncover a massive marriage fraud scheme in Montreal. Canada Politics, pp.

http://ca.news.yahoo.com/blogs/canada-politics/rcmp-uncover-massive-marriage-fraudscheme-montreal-214330214.html.

Canadian Broadcasting Company. (2011, September 19). True Love or Marriage Fraud?

Retrieved from CBC Documentaries:

http://www.cbc.ca/documentaries/passionateeyeshowcase/2010/truelove/

Canadian Council for Refugees. (2012). Violence Against Non-status, Refugee and Immigrant Women. Toronto: Canadian Council for Refugees.

CBC News. (2011, November 1). Marriage fraud targeted by Canada border agency. CBC Politics, pp. http://www.cbc.ca/news/politics/story/2011/11/01/marriage-fraud-canadaborder-agency.html.

CBC News. (2012, August 28). Man faces multiple charges in alleged bogus marriage scam. Canada. Retrieved from 
http://www.cbc.ca/news/canada/montreal/story/2012/08/28/montreal-amadou-niangmarriage-fraud-immigration-scam.html

Chetrit, S. L. (2012). Surviving an immigration marriage fraud investigation: all you need is love, luck, and tight privacy controls. Hein Law Review, 709-745.

Christensen, M. (2004). Manufacturing Subjectivities: Exploring the Role of Race and Biopower in the U.S. Immigration Policies. Carelton University, 1-75.

Citizenship and Immigration Canada. (2010, September 27). Backgrounders - Marriage fraudhave your say. Retrieved from Citizenship and Immigration Canada: http://www.cic.gc.ca/english/department/media/backgrounders/2010/2010-09-27.asp

Citizenship and Immigration Canada. (2011, February 28). Processing Applications to Sponsor Members of the Family Class. Retrieved from Citizenship and Immigration Canada: http://www.cic.gc.ca/english/resources/manuals/ip/ip02-eng.pdf

Citizenship and Immigration Canada. (2012, October 26). News Release - "The Jig is Up on Marriage Fraud, "says Minister Kenney. Retrieved from Citizenship and Immigration Canada: http://www.cic.gc.ca/english/department/media/releases/2012/2012-10-26.asp

Curry, B. (2008). Fraud squads chase down marriages of convenience. Canadians Against Immigration Fraud, 1-3.

De Hart, B. (2006). Introduction: The Marriage of Convenience in European Immigration Law. European Journal of Migration and Law, 251-262.

Diamond, T. A. (1981). The Tort of Bad Faith Breach of Contract: When if at all should it be extended beyond insurance transactions? Marquette Law Review - Hein Online, 64(3), 1.

Financial Times. (2013, June 10). Immigration rules on spouses work against executives, says research . Retrieved from Financial Times:

http://search.ft.com/search?queryText=foreign+spouse

Foucault, M. (1975-1976). Society must be defended: Lectures at the College de France. New York: Picador.

Foucault, M. (1977). Security, Territory, Population: Lectures At The College De France. Picador.

Foucault, M. (1978). The History of Sexuality Volume 1: An Introduction. Paris: Editions Gallimard. 
Government of Canada. (2012, October 25). Regulations Amending the Immigration and Refugee Protection Regulations. Retrieved from Canada Gazette: http://www.gazette.gc.ca/rppr/p2/2012/2012-11-07/html/sor-dors227-eng.html

Government of Canada. (2013, March 22). Forced Marriage. Retrieved from Travel Canada: http://travel.gc.ca/assistance/emergency-info/forced-marriage

Government of Canada. (2013, March 1). Regulatory Impact Analysis Statements. Retrieved from Citizenship and Immigration Canada: http://www.cic.gc.ca/english/department/media/backgrounders/2012/2012-03-02.asp

Greenhill, S. (2010, August 7). Silenced...the sham marriage whistleblower: Immigration officer claims he warned bosses but was forced out. London, United Kingdom.

Keung, N. (2013, February 7). From Cuba, yet another broken heart. Retrieved from The Star: http://www.thestar.com/search.html?page=2\&q=fraud\%20marriage

Keung, N. (2013, April 29). Marriage fraud: Canadian immigration officials tread thin line. Toronto, Ontario, Canada. Retrieved from http://www.thestar.com/news/immigration/2013/04/29/marriage_fraud_canadian_immigr ation_officials_tread_thin_line.html

Keung, N. (2013, February 7). Marriage to Cuban leaves Brampton bride brokenhearted - and broke. Retrieved from The Star: http://www.thestar.com/search.html?page=2\&q=fraud $\% 20$ marriage

Komiotis, W. (2012). Immigration Changes to Stop "Marriage Fraud" Increase Risk of Domestic Violence: Proposed amendments to Canada's immigration regulations will further endanger abused women and children. Marketwire.

Lincoln, \& Guba. (2003). Paradigmatic Controversies, Contradictions, and Emerging Confluences. In Denzin, \& Lincoln, The Landscape of Qualitative Research (pp. 253291). Thousand Oakes: Sage.

Lu, M. C.-W. (2005). Commercially Arranged Marriage Migration: Case Studies of Cross-border Marriages in Taiwan. Indian Journal of Gender Studies, 275-301.

Mackrael, K. (2013, October 26). Newlyweds moving to Canada must live together two years or risk deportation. Retrieved from The Globe and Mail: http://m.theglobeandmail.com/news/politics/newlyweds-moving-to-canada-must-livetogether-two-years-or-risk-deportation/article4678747/?service=mobile

Mehta, D. (2013, March 20). Sometimes marriage is a scam': Ottawa launches fresh ad campaign targeting immigration fraud. Retrieved from National Post - Canadian Politics: 
http://news.nationalpost.com/2013/03/20/sometimes-marriage-is-a-scam-ottawalaunches-fresh-ad-campaign-targeting-immigration-fraud/

Merali, N. (2009). Experiences of South Asian Brides entering Canada. Violence Against Women, 15(3), 321-339.

Merriam-Webster. (2013, July 29). Dictionary. Retrieved from Merriam-Webster Dictionary: http://www.merriam-webster.com/dictionary/marriage\%20of\%20convenience

Miller-Muro, L. (2011). Protections for Victims of Abuse. Encounters International, 1-5.

Morse, J. (1995). The Significance of Saturation. Qualitative Health Research, 147-149.

Nadesa, M. H. (2008). Governmentality, Biopower and Everyday Life. New York: Routledge.

Page, S. (2012, May 12). Questions linger about high-profile 'marriage fraud' case. Retrieved from National Post News: http://news.nationalpost.com/2012/05/13/questions-lingerabout-high-profile-marriage-fraud-case/

Parliament of Canada. (2012, March 8). Standing Committee on Citizenship and Immigration. Retrieved from Parliamentary Business: http://www.parl.gc.ca/HousePublications/Publication.aspx?DocId=5442362\&Language= E\&Mode $=1$

Parliament UK. (2013, July 2). Daily Hansard - Written Answers. Retrieved from Parliament Publications:

http://www.publications.parliament.uk/pa/cm201314/cmhansrd/cm130702/text/130702w 0001.htm

Potter, W. J., \& Levine-Donnerstein, D. (1999). Rethinking Validity and Reliability in Content Analysis. Journal of Applied Communication Research, 258-284.

Qayyum, I. (2010, May 3). Arranged marriages risk immigration scrutiny. Retrieved from CBC National News: http://www.cbc.ca/news/canada/toronto/story/2010/05/03/arrangedmarriages.html

Reuters. (2013, July 10). Currencies Quote. Retrieved from Reuters: http://www.reuters.com/finance/currencies/quote?srcAmt=18600\&srcCurr=GBP\&destA $\mathrm{mt}=\&$ destCurr $=\mathrm{CAD}$

Said, E. W. (1978). Orientalism. New York: Pantheon Books.

Statistics Canada. (2012). Canada-Permanent residents by category (spouses and dependants). Ottawa: Government of Canada.

Sunakawa, C. (2008). Discourse Analysis. Journal of Linguistic Anthropology, 13(2), 269 - 320. 
The Economist. (2011, November 12). Herr and Madame, Señor and Mrs. Retrieved from The Economist - International Marriage: http://www.economist.com/node/21538103

Travis, A. (2012, June 8). Stark choice under new immigration rules: exile or family breakup. Retrieved from The Guardian: http://www.theguardian.com/uk/2012/jun/08/immigrationrules-couples-stark-choice?guni=Article:in\%20body\%20link

UK Border Agency. (2013, July 10). Partner of a British Citizen or Settled Person. Retrieved from Home Office: UK Border Agency: http://www.ukba.homeoffice.gov.uk/visasimmigration/partners-families/citizens-settled/spouse-cp/can-you-apply/financial/

United Kingdom Border Agency. (2011, March 24). Sham marriages. Retrieved from News Story: Government of the United Kingdom:

https://www.gov.uk/government/news/damian-green-we-do-not-tolerate-sham-marriages

United Kingdom Border Agency. (2012, July 9). Immigration Directorate Instructions.

Retrieved from United Kingdom Border Agency Home Office:

http://www.ukba.homeoffice.gov.uk/sitecontent/documents/policyandlaw/IDIs/chp8annex/section-FM2.1.pdf?view=Binary

United Kingdom Border Agency. (2013, May 1). Sham marriage cases on BBC's Fake Britain. Retrieved from Home Office and UK Border Agency: https://www.gov.uk/government/news/sham-marriage-cases-on-bbcs-fake-britain

Van Dijk, T. (1999). Critical Discourse Analysis. Discourse in Latin America, 352-371.

Zaidi, A. U., \& Shuraydi, M. (2002). Perceptions of arranged marriages by young Pakistani Muslim women living in a western society. Journal of Comparative Family Studies, 495514. 